\title{
A Case of Renal Tubular Acidosis with Secondary Hypherparathyroidism, Lipemia and Aminoaciduria with Review of Japanese Literature
}

\author{
Fumio ETO, Takuo FUJITA, Gosuke INOUE \\ AND MASAKI YOSHIKAWA \\ Department of Geriatrics, University of Tokyo Faculty of Medicine, \\ Bunkyo-ku, Tokyo 113
}

\begin{abstract}
Synopsis
A 44 year old female with renal tubular acidosis, osteomalacia, lipemia and aminoaciduria is reported. Mild hypocalcemia, marked hypophosphatemia and elevated serum alkaline phosphatase were associated with high serum immunoreactive parathyroid hormone level, which was promptly suppressed by intravenous calcium infusion, indicating secondary hyperparathyroidism. Among 56 cases of renal tubular acidosis so far reported in Japan, patients in the first decade predominated and the male to female ratio was 1 to 3 . Osteomalacia was found in 19 and hypergammaglobulinemia in 11 but aminoaciduria was seen only in 2. Marked lipemia was the most unusual aspect in the present case.
\end{abstract}

Among a spectrum of renal tubular dysfunction leading to disturbance of calcium and phosphorus metabolism and osteomalacia, renal tubular acidosis is one of the most common varieties (Wrong et al., 1959; Elkinton 1960; Elkinton et al., 1960), and a considerable number of cases have already been reported in Japan. Combination of primary renal tubular acidosis with aminoaciduria and lipemia, however, is rather unusual, and the role of parathyroid hormone in this syndrome still remains controversial (Reiss et al., 1973). We have recently experienced such a case, which is the subject of the present report, along with the review of Japanese literature.

\section{Case Report}

K. T., a 44 year old housewife, was admitted to the Department of Geriatrics, University of Tokyo Hospital, on May 7, 1973 with chief complaints of thirst, polyuria, arthritis and lumbago.

Family History was non-contributory ex-

Received for publication April 19, 1974. cept for her father who died of apoplexy at the age of 58 and her sisters with teeth extremely susceptible to carious changes. No consanguinity is known.

Past History indicated the birth at term following normal gestation, followed by a rather slow but usual growth through infancy and childhood. Despite irregular eating habits and somewhat unbalanced diet, her nutritional conditions remained satisfactory. Her teeth were so susceptible to carious change that she became edentulous already in her twenties. At the age of 8 , she suffered from peritonitis of probably tuberculous nature and recovered without complications. Menarche was at 18 and menopause as early as 39 . Since her marriage at 27 , no pregnancy ever occurred. She had average intelligence and school achievement.

The present illness apparently started with thirst and polyuria in her teens. Her gait became unstable due to acute left coxitis at the age of 19 , followed by fracture of the left femoral neck without remarkable trauma. After application of the plaster of Paris cast for 3 months, her left hip became ankylosed. 
At 28, she experienced high fever with pain in the extremities and lumbago repeatedly. Since the age of 35 she developed excessive appetite and gained weight. After the detection of hypertension of $220 / 110$ was at age 42 , she was referred to us under the suspicion of renal tubular acidosis at 44 .

Physical examination revealed a well developed, well nourished woman, $150 \mathrm{~cm}$ in height and $47 \mathrm{~kg}$ in weight, with blood pressure of 180/110 and mild arteriosclerotic changes of ocular fundi. Skin was free of xanthelasma or edema. Pelvis, femora and tibiae were tender to compression. The range of movement was reduced markedly in the left hip and moderately in the left ankle.

Laboratory tests revealed BSR $12 \mathrm{~mm} / \mathrm{hr}$, CRP 3+, ASLO less than 100, negative Wasserman reaction and rheumatoid factor. Hemoglobin was $14.6 \mathrm{~g} / 100 \mathrm{ml}$, RBC $491 \times$ $10^{4}$, platelet $16.5 \times 10^{4}$ and $\mathrm{WBC} 3,900 / \mathrm{mm}^{3}$ with normal differential count. Urinalysis revealed $\mathrm{pH} 6.5$, specific gravity $1.013,1+$ protein, and negative sugar with 1-5 RBC and 10-20 WBC per HPF. Feces was of normal color and consistency without detectable fat droplets. Serum uric acid was $9.8 \mathrm{mg}$, cholesterol $295 \mathrm{mg} / 100 \mathrm{ml}$, triglycerides $258 \mathrm{mg} / 100 \mathrm{ml}$, free fatty acids 1028 $\mu \mathrm{Eq} / \mathrm{L}$, and total lipids $1,032 \mathrm{mg} / 100 \mathrm{~m} l$. Serum lipoproteins on paper electrophoresis revealed elevated pre- $\beta$-lipoprotein, elevated and narrow $\beta$-lipoprotein in the absence of chiromicron peak, indicating type II hyperlipoproteinemia. EKG revealed ST segment depressions in leads II, aVL and V3 through V6, suggesting myocardial damage. Arterial blood gas studies revealed $\mathrm{pH}$ 7.33, $\mathrm{pO}_{2}$ $88 \mathrm{mmHg}, \mathrm{O}_{2}$ saturation $96 \%, \mathrm{pCO}_{2} 32$ $\mathrm{mmHg}$, buffer base $41.5 \mathrm{mEq} / \mathrm{L}$, standard bicarbonate $16.5 \mathrm{mEq} / \mathrm{L}$, actual bicarbonate $16.5 \mathrm{mEq} / \mathrm{L}$ and total $\mathrm{CO}_{2} 17.4 \mathrm{mEq} / \mathrm{L}$. PSP excretion was $25 \%$ in 15 minutes and $73 \%$ in $2 \mathrm{hr}$ and Fishberg's concentration test revealed the highest urinary specific gravity of 1.016 , and osmotic pressure $450 \mathrm{~m} \mathrm{Osm} / \mathrm{kg} \mathrm{H}_{2} \mathrm{O}$. GFR was $77 \mathrm{ml}$, and RPF $213 \mathrm{ml} / \mathrm{min}$, with filtration fraction of 0.36 . BMR was $-6 \%$, PBI $3.22 \mu \mathrm{g} / 100 \mathrm{ml}$, urinary $170 \mathrm{HCS} 2.7-$ $3.6 \mathrm{mg} / 24 \mathrm{hr}$, and $17 \mathrm{KS} 3.2-3.6 \mathrm{mg} / 24 \mathrm{hr}$. Blood sugar and serum immunoreactive insulin (IRI) before and 30, 60, 90, 120 and 180 min after oral load of 100 gram glucose was $80,145,196,188,158$ and $116 \mathrm{mg} / 100 \mathrm{ml}$ and $21.7,106.5,107.9,119.1,149.3$ and $112.5 \mu \mathrm{U} /$ $\mathrm{m} l$, respectively. Despite oral loading of $0.1 \mathrm{~g} / \mathrm{kg}$ ammonium chloride, $\mathrm{pH}$ of urine stayed above 5.7 , when blood $\mathrm{pH}$ was as low as 7.26, as shown in Fig. 1. Analysis of amino acid content of urine revealed a definite increase of cystine and lysine, with a slight increase of threonine, methionine and alanine but other amino acids in normal concentrations, as shown in Table 1.

Serum Ca was 8.35 and inorganic P 1.91 $\mathrm{mg} / \mathrm{d} l$, alkaline phosphatase 17.8 and 24.3 King-Armstrong units and \%TRP $60 \%$. On the day of intravenous infusion of $15 \mathrm{mg} \mathrm{Ca} /$ $\mathrm{kg}$ according to the method of Haas (1966)

Table 1. Amino acid in urine, $\mu$ mole/ 24 hours

\begin{tabular}{|c|c|c|c|}
\hline Amino Acid & March 1973 & May 1973 & Dec 1973 \\
\hline Taurine & 770 & & \\
\hline Aspartic Acid & 28 & & 128 \\
\hline Threonine & 227 & 450 & 434 \\
\hline $\begin{array}{l}\text { Asparagine } \\
\text { Glutamine }\end{array}$ & & & \\
\hline Serine & 452 & 496 & 503 \\
\hline Glutamic Acid & 26 & + & 98 \\
\hline Proline & 64 & low & + \\
\hline Citrulline & 22 & & low \\
\hline Glycine & 782 & 640 & 1618 \\
\hline Alanine & 302 & 340 & 266 \\
\hline Valine & 39 & 34 & 49 \\
\hline Cystine & 239 & 270 & 276 \\
\hline Methionine & $\overline{\text { low }}$ & 92 & + \\
\hline Isoleucine & 16 & + & 39 \\
\hline Leucine & 34 & 50 & 49 \\
\hline Tyrosine & 41 & + & 69 \\
\hline Phenylalanine & 29 & + & 59 \\
\hline$\beta$-AIBA & 950 & & \\
\hline Lysine & 832 & 690 & 440 \\
\hline Histidine & 697 & 916 & + \\
\hline Arginine & 32 & + & 69 \\
\hline
\end{tabular}

Underlined values were consistently supernormal. 


\section{Ammonium Chloride Loading Test}

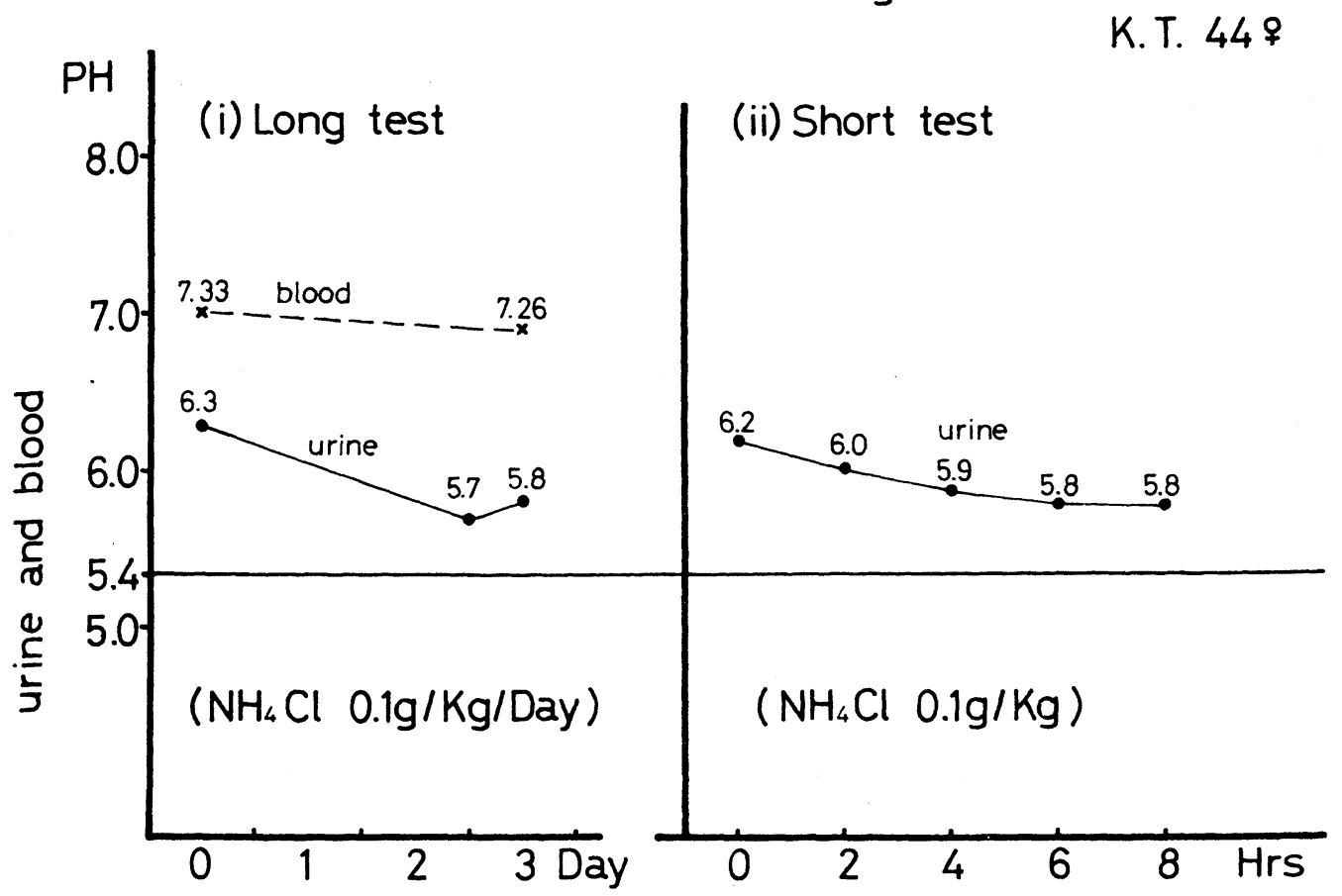

Fig. 1. Ammonium chloride loading test. In the long test, $0.1 \mathrm{~g} / \mathrm{kg} /$ day of $\mathrm{NH}_{4} \mathrm{Cl}$ was orally administered for 3 days and urine $\mathrm{pH}$ was measured on day 2 and 3 . In the short test, $0.1 \mathrm{~g} / \mathrm{kg} \mathrm{NH}{ }_{4} \mathrm{Cl}$ was administered and $\mathrm{pH}$ of hourly urine specimen was measured. In none of these specimen, $\mathrm{pH}$ went down below 5.7. Since at least one specimen should give $\mathrm{pH}$ below 5.4, diagnosis of renal tubular acidosis was made.

urinary calcium excretion showed only a slight increase from the level on the control day, indicating retention of $90 \%$ of the infused $\mathrm{Ca}$, or a marked avidity of the skeleton for the calcium. Serum immunoreactive parathyroid hormone measured by the method of Fujita et al. (1972) $2.9 \mathrm{ng} / \mathrm{ml}$ (normal level, 0$0.6 \mathrm{ng} / \mathrm{ml}$ ) and definitely suppressed by calcium infusion as shown in Fig. 2, indicating secondary hyperparathyroidism. Bone X-ray picture revealed a general decrease of density, calcification or ossification of ligaments surrounding joints, periosteal thickening of the upper left humerus, pseudofracture of the left pubic arch and right femur (Fig. 3) and ankylosis of the left hip and sacroiliac joint. Intravenous pyelography and aortography revealed hopoplastic left kidney with irregular contour but without stenosis of the renal artery.

Under the diagnosis of primary renal tubular acidosis of distal type, treatment with 50,000 units of Vitamin $\mathrm{D}_{2}$ and $30 \mathrm{ml}$ of Shohl's solution, sodium citrate and citric acid mixture, was given daily. After 2 weeks, arterial blood $\mathrm{pH}$ rose to 7.38, $\mathrm{pCO}_{2} 40$ $\mathrm{mmHg}$, and actual bicarbonate $23.4 \mathrm{mEq} / \mathrm{L}$, with gradual improvement of pains in bones and joints.

\section{Discussion}

Systemic acidosis with persistently alkaline urine even after ammonium chloride loading definitely places the present case in the group 


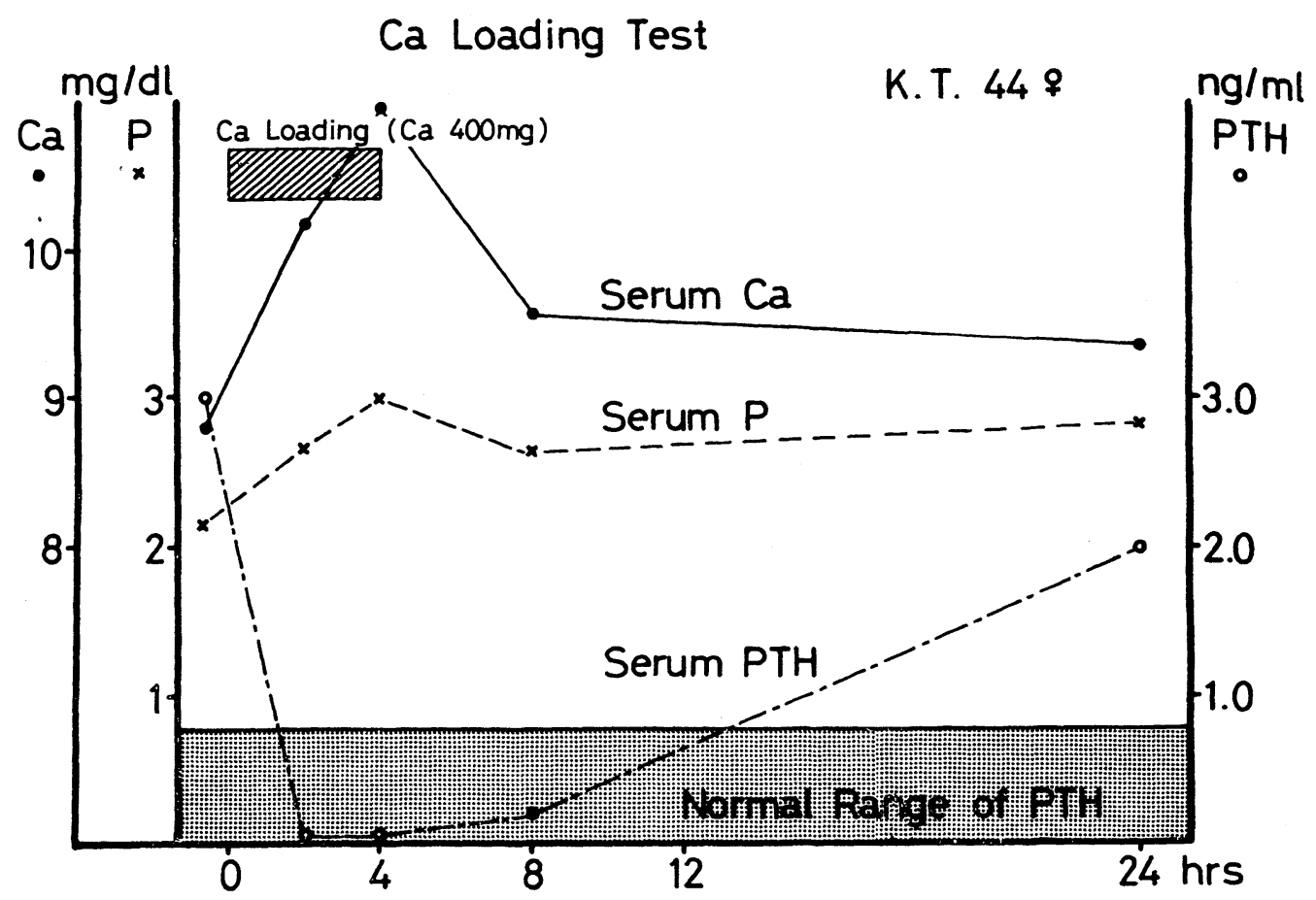

Fig. 2. Calcium loading test. Serum immunoreactive PTH was definitely elevated before infusion of Ca-gluconate containing $15 \mathrm{mg} \mathrm{Ca}$ and became undetectable during induced hypercalcemia, again rising $24 \mathrm{hrs} \mathrm{later.}$

of renal tubular acidosis, of which numerous studies are already available with attempts of classification and elucidation of pathophysiological mechanism. After the first description by Butler et al. (1936) of acidosis in children with diffuse nephrosclerosis, Albright (1942) described a group of patients with osteomalacia, nephrocalcinosis and metabolic acidosis and called this disease tubular insufficiency without glomerular insufficiency. Pines and Madge (1951) introduced the currently used term renal tubular acidosis.

Tsuda et al. (1962) was apparently the first to describe this syndrome as such in Japan, though many cases had no doubt escaped proper description and report before this time. Fifty-six cases of renal tubular acidosis, with defects in urinary acidification due to distal tubular insufficiency without overt renal failure have so far been reported in Japanese literature. The age distribution indicates a
Table 2. Age and sex distribution of cases of tubular acidosis in Japan

\begin{tabular}{cccc}
\hline Age in Years & Male & Female & Total \\
\hline $0-9$ & 7 & 12 & 19 \\
$10-19$ & 2 & 5 & 7 \\
$20-29$ & 0 & 6 & 6 \\
$30-39$ & 0 & 8 & 8 \\
$40-49$ & 4 & 7 & 11 \\
$50-59$ & 0 & 4 & 4 \\
$60-$ & 0 & 0 & 0 \\
Adult & 1 & 0 & 1 \\
Total & 14 & 42 & 56 \\
\hline
\end{tabular}

preponderance in the first decade, and the disease occurred in the first year of life in 2 cases (Table 2). Male to female ratio was 1:3. Urinary tract infection was described in 11 and nephrocalicnosis in 26 , probably facilitated by alkaline urine. Hypergammaglobulinemia was found in 11 and Sögren syndrome in 4 , suggesting an autoimmune mechanism 


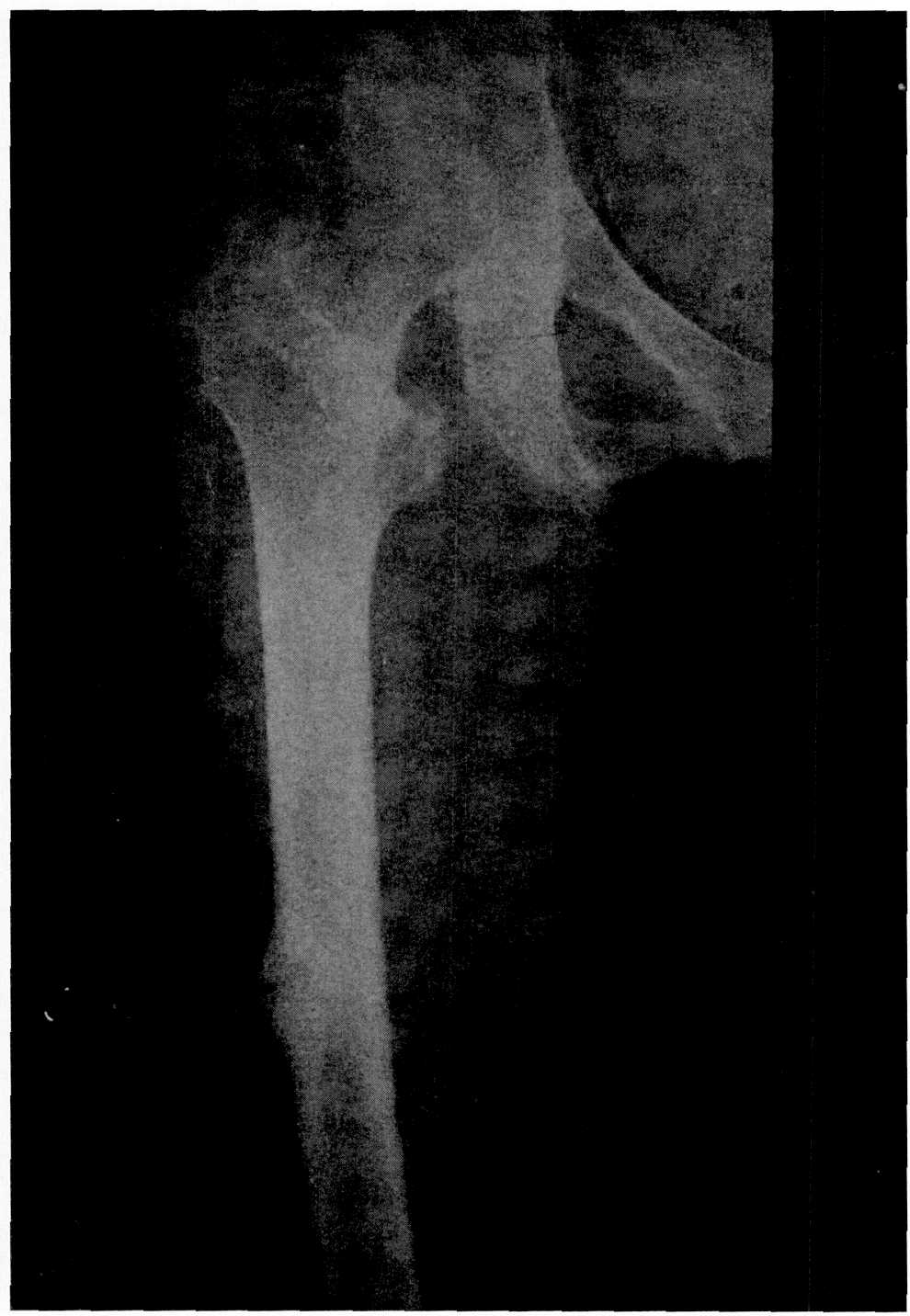

Fig. 3. Pseudofracture of the right femur.

(Morris et al., 1968). Distal tubular involvement leading to urinary concentration and polyuria in Sögren syndrome was found in 8 cases collected by Kahn et al. (1962). Serum was normal in 23 and low in 2, serum inorganic phosphorus low in 21 and normal in 6, and serum alkaline phosphatase high in 17 and low in 5 among cases with such measurement. Aminoaciduria was seen in 4 and data on quantitative analysis are available in 2 .
One is a 20 year old female excreting excessive amount of histidine, serine, tyrosine, threonine and glutamine and the other is the present case with excessive amount of cystine, lysine, threonine, and alanine in urine. Glycosuria was seen in none of these 4 cases. Muldowney et al. (1968) pointed out the role of secondary hyperparathyroidism in the development of aminoaciduria in osteomalacia, based on the reversibility in response to treatment. Amino- 
aciduria persisted after 6 months of treatment and correction of acidosis and hypocalcemia in the present case. Osteomalacia or rickets were found in 19 of 56 cases. The present case apparently occupies a rather unique position, representing 1 of the 2 cases with aminoaciduria and the only case with definite lipemia among 56 cases of primary renal tubular acidosis so far reported in Japan. These complications may represent separate familial or genetic abnormality along with the distal tubular problem.

\section{References}

Albright, F., C. H. Burnett, P. F. Smith and W. Parson (1942). Endocrinology 30, 922.

Butler, A. M., J. L. Wilson and S. Farber (1936). J. Pediatrics, 8, 489.

Elkinton, J. R. (1960). Amer. J. Med. 28, 165. Elkinton, J. R., E. J. Huth, G. D. Webster,
Jr. and R. A. McCance (1960). Amer. J. Med. 29, 554.

Fujita, T., H. Orimo, K. Okano and M. Yoshikawa (1972). J. Bone and Joint Surg. 54, 181.

Haas, H. G. (1966). Knochenstoffwechsel und Parathyreoidea Erkrankungen, Thieme.

Kahn, M., A. D. Meritt, M. J. Wahl and J. Orloff (1962). Ann. Intern. Med. 56, 883.

Morris, R. C., Jr., A. Sebastian and E. Morris (1968). J. Clin. Invest. 47, 70a.

Muldowney, F. P., Frearey, R. and D. McGeeney (1968). Quart. J. Med. 148, 517.

Pines, K. L. and A. H. Mudge (1951). Amer. J. Med. 11, 302.

Reiss, E. and J. M. Canterbury (1973). Ann. Rev. Med. 24, 217.

Tsuda, J., F. Takiguchi, M. Konno and T. Togo (1962). Shonika Rinsho (In Japanese) $15,1256$.

Wrong, O. and H. E. F. Davies (1959). Quart. J. Med. 28, 259. 